\title{
TOXICOLOGIA DOS COSMÉTICOS: AVALIAÇÃO DOS RISCOS QUE OS PRODUTOS CAPILARES TRAZEM À SAÚDE
}

\author{
COSMETIC TOXICOLOGY: ASSESSMENT OF THE RISKS THAT HEALTH \\ PRODUCTS BRING TO HEALTH
}

\author{
Vagner Alexandre de SOUSA ${ }^{1}$, Francisca Dara Augusto de SOUSA², \\ Ana Emília Formiga MARQUES 3 , Breno Alves Auad MOREIRA ${ }^{4}$
}

\begin{abstract}
1 - Graduando de Farmácia da Faculdade São Francisco da Paraíba - FASP, Cajazeiras - PB, Brasil
2 - Pós-graduanda de Análises Clínicas da Faculdade Santa Maria - FSM, Cajazeiras - PB, Brasil

3 - Professora de Farmácia Clínica, Curso de Farmácia, Faculdade São Francisco da Paraíba - FASP, Cajazeiras - PB, Brasil 4 - Professor de Farmacobotânica, Curso de Farmácia, Faculdade São Francisco da Paraíba-FASP, Cajazeiras - PB, Brasil Autor para correspondência:vg.alexandree@gmail.com
\end{abstract}

\section{RESUMO:}

Nas últimas décadas o uso de produtos capilares tem se tornado um hábito no cotidiano dos brasileiros e a cada dia o seu consumo cresce gradativamente, dessa forma ressaltase a importância de pesquisar a existência de efeitos indesejados. O objetivo deste trabalho foi descrever os riscos potenciais à saúde humana que os produtos capilares, utilizado nos procedimentos de alisamento e tingimento capilar, podem oferecer. Tratou-se de um estudo descritivo, com abordagem qualitativa, através de levantamento bibliográfico, referente ao período de 2007 a 2017. Neste trabalho, foi analisado os casos de notificações de intoxicação humana por cosméticos, através dos bancos de dados do NOTIVISA e SINITOX. No sistema NOTIVISA foram registrados, no período de 2007 a 2015, 1.715 casos, onde o maior número de notificações se dá no ano de 2015, com 278 casos, que equivalem a $16.2 \%$ do total. Enquanto no sistema de dados do SINITOX, foram identificados 9.113 casos, entre os anos de 2007 a 2013, sendo que o maior número de notificações ocorreu no ano de 2011, com 1.669 casos registrados, que representam $18.3 \%$ do total. Após análise dos dados, conclui-se que existem relatos na literatura de reações adversas a cosméticos, embora não sejam desejáveis, podendo provocar sérios danos à saúde dos indivíduos expostos, quando utilizados inadequadamente.

Palavras-Chave: Toxicologia dos Cosméticos. Cosmetovigilância. Reações Adversas. Produtos Capilares.

\section{ABSTRACT:}

In the last decades, the use of hair products has become a habit in the daily life of Brazilians and every day its consumption grows gradually, that way it is important to investigate the existence of undesired effects. The objective of this paper was to describe the potential risks to human health which the hair products bring, used in hair straightening and colouring procedures, can offer. It was a descriptive study, with qualitative approach, through a bibliographical survey, referring to the period from 2007 to 2017. In this work, were analyzed cases of reports of human intoxication by cosmetics, through the databases NOTIVISA e SINITOX. In the NOTIVISA system were registered, in the period of 2007 to $2015,1.715$ cases, where the highest number of notifications occured in the year of 2015, with 278 cases, equivalent to $16.2 \%$ of the total. While in the SINITOX data system, were identified 9.113 cases between 2007 and 2013, with the highest number of notifications occurred in 
2011 , with 1,669 registered cases, representing $18.3 \%$ of the total. After analyze data, it is concluded that there are reports in the literature of adverse reactions to cosmetics, although they are not desired, may cause serious damage to the health of exposed individuals when used improperly.

Keywords: Toxicology of Cosmetics. Cosmetovigilance. Adverse reactions. Hair Products.

\section{INTRODUÇÃO}

Produtos cosméticos são aqueles de uso externo nas diversas partes do corpo humano (pele, sistema capilar, unhas, lábios, órgãos genitais externos, dentes e membranas mucosas da cavidade oral), com o objetivo de limpar, perfumar, alterar sua aparência, corrigir odores corporais, proteger ou manter em bom estado (LACRIMANTE e RIBEIRO NETO, 2014).

Nas últimas décadas, o uso de cosméticos tem se tornado um hábito no cotidiano dos brasileiros e a cada dia o seu consumo cresce gradativamente. Segundo os dados relatados pela ABIHPEC (Associação Brasileira da Indústria de Higiene Pessoal, Perfumaria e Cosméticos), atualmente o Brasil se encontra entre os maiores países consumidores de produtos de beleza, representando cerca de $7,1 \%$ do consumo mundial, ocupando a quarta posição no ranking em produtos de HPPC (Higiene pessoal, perfumaria e cosméticos), ficando atrás apenas dos Estados Unidos, China e Japão (ABIHPEC, 2016).

De acordo com o Caderno de Tendências 2014-2015 publicado pela ABIHPEC, a categoria "Produtos para Cabelos" domina nos mercados da América Latina, principalmente no Brasil, tendo em 2012 uns dos melhores anos de crescimento, faturando cerca de $\mathrm{R} \$$ 18,1 bilhões (ABIHPEC, 2017).

De certa forma, os produtos cosméticos geralmente não são associados com sérios danos à saúde. Porém, isto não quer dizer que estes sejam sempre seguros, especialmente considerando os efeitos a longo prazo, (ANVISA, 2013).

Diante do grande consumo de cosméticos, em especial de produtos capilares, ressalta-se a importância de se pesquisar a existência de efeitos indesejados e as condições de exposição a esses produtos, além da composição da formulação, que pode conter substâncias restritivas. Tais substâncias foram determinadas pela Agência Nacional de Vigilância Sanitária (ANVISA), órgão do Ministério da Saúde, na Resolução da Diretoria Colegiada $n^{\circ} 3$, de 18 de janeiro de 2012, estabelecendo a lista de substâncias que os produtos de higiene pessoal, cosméticos e perfumes não devem conter exceto nas condições estabelecidas (SILVA, 2017). 
Apesar das substâncias químicas presentes na formulação dos produtos capilares, estarem em pequenas quantidades, o perigo que apresentam é inegável. Partindo dessas reflexões, surgiu a necessidade de se saber quais os riscos que os produtos capilares podem trazer à saúde. Portanto, faz-se necessário um levantamento mais detalhado do assunto do tema em estudo, supondo-se que a formulação de produtos capilares pode conter substâncias potencialmente perigosas à saúde.

Assim, este trabalho se justifica pela urgência de se buscar mais dados em relação aos riscos que esses produtos oferecem, não só aos usuários, mas também aos profissionais da beleza, que diariamente ficam expostos a esses cosméticos e necessitam de um conhecimento maior, no intuito de se evitar malefícios indesejáveis. Logo, surge à preocupação quanto à manifestação de reações adversas e efeitos tóxicos. Desta forma, este estudo tem como finalidade contribuir para enriquecer ainda mais a bibliografia sobre os riscos prejudiciais à saúde do consumidor que irá fazer uso de produtos capilares, fornecendo informações para futuras pesquisas.

\section{MATERIAL E MÉTODOS}

Este estudo trata-se de uma revisão bibliográfica, de caráter descritivo, com abordagem qualitativa.

Segundo Marconi e Lakatos (2010), a abordagem qualitativa procura analisar e interpretar aspectos profundos, descrevendo a complexidade do comportamento humano, favorecendo análise detalhada sobre investigações, hábitos, atitudes e tendências de comportamento.

As fontes utilizadas para a realização dessa revisão são de origem literária cientifica, retiradas de revistas e artigos científicos, referentes ao período de 2007 a 2017. Os artigos foram adquiridos através de pesquisas eletrônicas dos sites da ANVISA, ABIHPEC, ABDI, CVS, INCA e o site do Ministério da Saúde. Além destas fontes foi também utilizado para a pesquisa, revistas cientificas, trabalhos de conclusão de curso, dissertações e livros específicos da área.

Os critérios de inclusão foram: informações retiradas de artigos científicos, além de dissertações, trabalhos de conclusão de curso e trabalhos acadêmicos que delimitassem os objetivos do referido estudo, publicados nos últimos dez anos.

Os critérios de exclusão foram: trabalhos publicados antes de 2007, que estivessem em outro idioma que não fosse português ou inglês e estudos que não abordassem o tema. 
Para a pesquisa dos artigos foram utilizadas as palavras-chave: toxicidade, toxicologia dos cosméticos, cosmetovigilância, reações adversas, produtos capilares.

\section{RESULTADOS E DISCUSSÃO}

No levantamento bibliográfico para essa pesquisa, foram acessadas as bases de dados da ANVISA, ABIHPEC, ABDI, CVS, INCA, Revistas Cientificas e o site do Ministério da Saúde. Em outros sites de bases acadêmicas não foi encontrado nenhum artigo.

Para a constituição desse estudo foram identificados 56 manuscritos, no total obteve-se: no site do Ministério da Saúde, foram obtidos 22 artigos na totalidade, sendo que somente 13 foram selecionados, na ABIHPEC e ABDI dos quais foram obtidos 10, sendo que 4 foram selecionados, trabalhos de conclusão de curso (TCCs) e dissertações, 6 artigos foram obtidos, mas somente 4 foram selecionados de acordo com os critérios de inclusão, nas Revistas Cientificas 18 artigos obtidos e 13 selecionados. A seleção foi realizada a partir da leitura criteriosa dos artigos encontrados nas bases de dados, após a análise de todo o material, verificou-se que 34 manuscritos atendiam aos critérios de inclusão definidos neste estudo, sendo que 22 foram descartados, em razão de não estarem dentro dos critérios ou por não apresentarem nenhuma relevância para a pesquisa (Fluxograma 1).

FLUXOGRAMA 1 - FLUXOGRAMA DAS LITERATURAS IDENTIFICADAS E SELECIONADAS SEGUNDO A BASE DE DADOS.

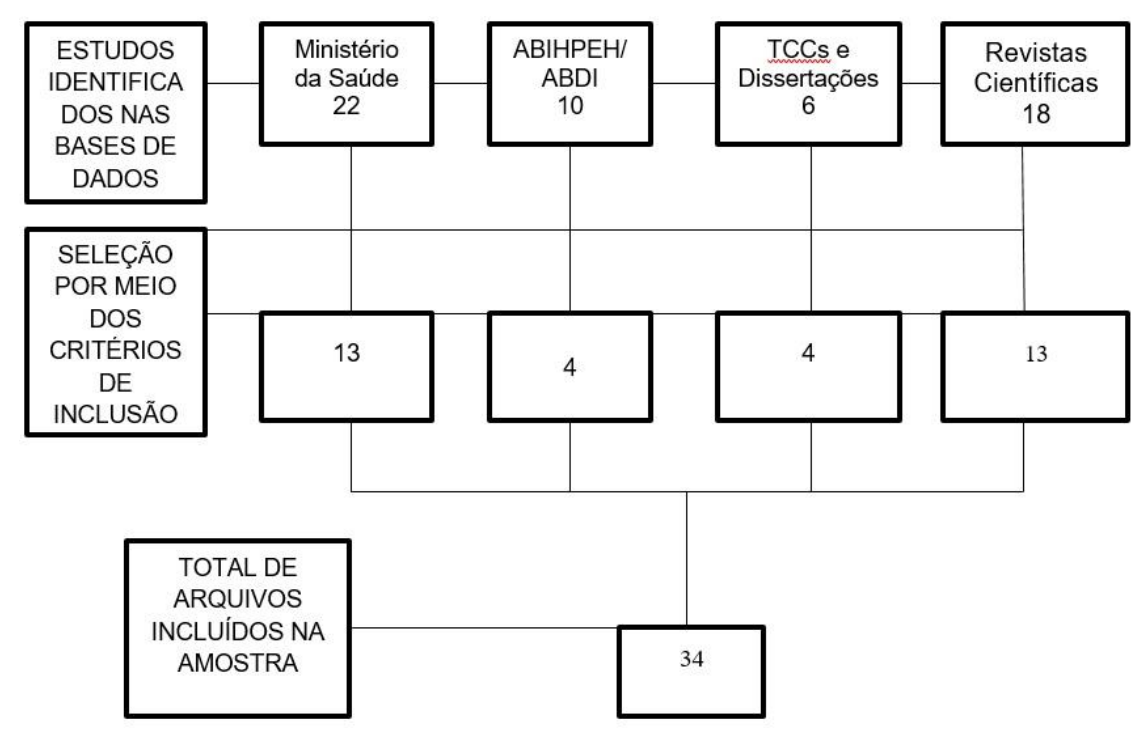


Após análise do fluxograma e do material bibliográfico, muitos artigos deixam notório da importância de se identificar quais os riscos que os produtos cosméticos, especialmente os produtos capilares, possam apresentar pelo seu uso, o qual pode advir da composição dos produtos ou da utilização inadequada.

As reações adversas a cosméticos geralmente consistem em reações irritativas imediatas ou acumulativas, reações alérgicas ou sensibilizantes, dermatites por fotossensibilização, reações físicas por oclusão folicular, reações sistêmicas por inalação ou contato oral, por absorção percutânea ou ação carcinogênica (CHORILLI et al, 2007).

Os trabalhos reportados na literatura indicam que os compostos químicos presentes nas tinturas capilares como corantes, precursores, acopladores, aditivos entre outros são consi-7deradas as substâncias mais reativas da indústria cosmética. Alguns autores associam que precursores tais como resorcinol, usado como ingrediente na formulação de corantes, atuam como desreguladores endócrinos afetando a função da tireoide. Outros precursores usados em tinturas permanentes, como o p-fenilenodiamina (PPD), têm levantado preocupações para a saúde humana devido a riscos associados a alergias, dermatites e nefrotoxidade (OLIVEIRA et al, 2014).

Estudos mostraram que o PPD pode induzir o processo de apoptose das células e reduzir a viabilidade célular. Alguns autores associaram o seu uso com a incidência de câncer devido à presença dos componentes ou seus derivados na urina de usuários, indicando que os compostos cancerígenos, de fato, alcançam o órgão alvo quando relacionado ao uso regular de corantes de cabelo (CARDOSO e ROCHA, 2019).

Sabe-se que a expo-sição aguda a essa substância, pode causar graves tipos de dermatites, irritação nos olhos e asma, principalmente em profissionais que aplicam as tinturas e, em casos de ingestão acidental, pode levar a quadros graves de intoxicação, induzindo a gastrite, a insuficiência renal, a vertigem, os tremores, as convulsões e o coma em seres humanos (KASI et al, 2015).

É importante mencionar que a incidência de reações alérgicas induzidas pela utilização de tinturas, principalmente devido à presença de PPD, tem sido gradativamente reduzida devido à utilização de luvas durante o processo de tingimento e às advertências nos rótulos dos produtos sobre a necessidade de realização do teste de sensibilidade antes da aplicação (OLIVEIRA et al, 2014).

Nos procedimentos de aplicação de tinturas capilares, o uso do acetato de chumbo em formulações cosméticas, possui efeito cumulativo no organismo e em grande quantidade provoca intoxicação (BRASIL, 2013). 
Em relação aos produtos de alisamento capilar, os ingredientes ativos encontrados em sua composição são o ácido tioglicólico e os hidróxidos de sódio, potássio, cálcio, entre outros. O cabelo alisado com hidróxido de sódio pode danificar os fios, produzir queimaduras no couro cabeludo, até mesmo cegueira caso atinja os olhos, além de sofrer uma grande perda de proteínas, e, quando usado em cabelos já submetidos a processos de tingimento essa perda é significativamente maior, pois tende a danificar mais ainda a parte interna do fio de cabelo (FERREIRA, 2015).

Trata-se de um produto restrito ao uso por profissional, produzindo um alisamento químico permanente e de eficiência máxima. Apesar de ser visto como o alisante mais potente e rápido, é o que possui ação mais agressiva ao cabelo e ao couro cabeludo, sendo indicado para cabelos muito crespos e resistentes. Os hidróxidos de potássio e cálcio possuem efeitos semelhantes ao hidróxido de sódio, apesar de ser mais brando. O ácido tioglicólico é o mais utilizado no Brasil. É considerado menos potente, pois danifica menos os cabelos do que os hidróxidos (MACHADO et al, 2017).

Segundo a Agência Internacional de Pesquisa em Câncer, o IARC (International Agency For Research on Cancer), os profissionais cabeleireiros fazem parte de um grupo de profissionais mais expostos a uma gama de produtos cancerígenos entre os quais destaca-se o formol (INCA, 2016).

O formol é considerado um produto cancerígeno pela IARC. Foi comprovada a incidência de câncer nas vias respiratórias superiores (nariz, faringe, laringe, traqueia e brônquios) pela inalação da substância (BRASIL, 2016).

Um exemplo da utilização de formol se dá na Escova Progressiva, que é um procedimento no qual se faz o uso indevido dessa substância perigosa como alisante, podendo causar sérios danos à saúde (BRASIL, 2007).

O uso do formol como alisante capilar não é permitido pela ANVISA, pois esse desvio de uso pode acarretar sérios danos à saúde do usuário que receber o produto e também do profissional que aplica o produto com formol. A exposição aguda e subaguda dessa substância pode causar irritação, coceira, queimadura, descamação e vermelhidão do couro cabeludo e do rosto, queda do cabelo, irritação ocular, falta de ar, cefaleia, ardência e coceira no nariz, devido ao contato direto com a pele ou com vapor formado por causa do aquecimento dos fios através do uso do secador e da prancha alisadora que provocam a evaporação da substância. Múltiplas exposições podem causar também boca amarga, dores de barriga, enjôos, vômitos, desmaios, feridas na boca, narina e olhos, e câncer nas vias aéreas superiores (nariz, faringe, laringe, traqueia e brônquios), podendo 
até levar à morte (ANVISA, 2009; MACAGNAN; SARTORI; CASTRO, 2011).

Conforme a Resolução RDC N³6, de 17 de junho de 2009, foi proibida a comercialização do formol em estabelecimentos como drogarias, farmácias, supermercados, empórios, lojas de conveniências e drugstores, com o objetivo de restringir o acesso da população a esse tipo de substância, coibindo o desvio de uso do formol como alisante capilar, protegendo a saúde de profissionais cabeleireiros e consumidores (ANVISA, 2009).

Embora o uso do formaldeído tenha sido proibido pelos órgãos reguladores, em concentrações que não sejam com função conservante, ele ainda é utilizado em locais para alisamento capilar, por meio de produtos irregulares ou através da adição intencional pelo profissional que realiza a aplicação (MACAGNAN; SARTORI; CASTRO, 2011).

De acordo com dados da literatura, o ácido glioxílico quando submetido a altas temperaturas libera formol e isso compromete à saúde do consumidor e do profissional do salão de beleza (Figura 1). A ANVISA adverte que não existem dados de segurança e eficácia que confirmem o uso do ácido glioxílico em produtos com ação alisante e/ou submetido a tratamento térmico. Sendo dessa forma um risco para a saúde do consumidor, e do profissional de salão de beleza. Ela ainda conclui
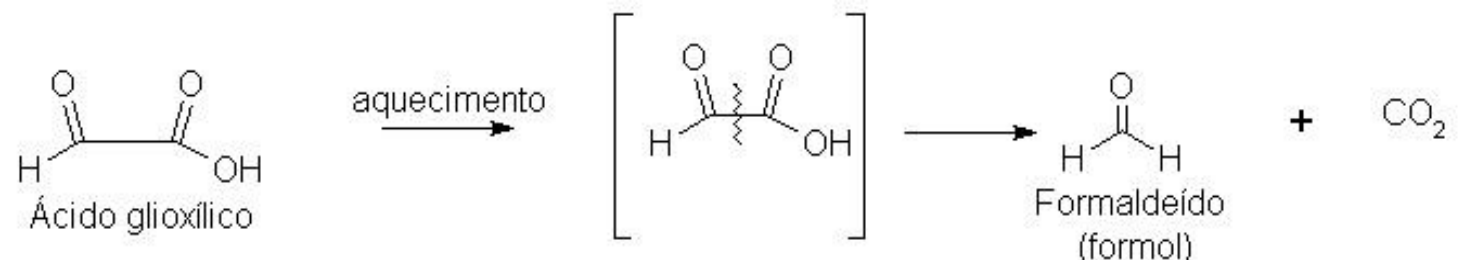

(formol)

\section{FIGURA 1 - FORMAÇÃO DO FORMALDEÍDO A PARTIR DO AQUECIMENTO DO ÁCIDO FONTE: PORTILHO, 2014.}

Outro composto presente em cremes alisantes, é o tioglicolato de amônio que pode causar dermatite de contato e irritação na pele. O tioglicolato não é compatível com os hidróxidos à aplicação simultânea dos dois produtos sobre a mesma área acarretará queda capilar. Segundo Olasode (2009), os produtos relaxantes que continham em sua composição hidróxido de sódio ou tioglicolato de amônio como composto ativo documentados em auto-relatos, causaram os seguintes efeitos adversos: caspa, prurido do couro cabeludo, queimaduras no couro cabeludo, cicatrizes de couro cabeludo, enfraquecimento do cabelo, quebra do fio, perda de cabelo no couro cabeludo e mudança 
na cor do cabelo. Dermatite alérgica de contato para produtos com tioglicolato foram relatados. Necrose do couro cabeludo e descoloração do cabelo têm sido relatados comumente como sequela de alisamentos. (VARELA, 2007; OLASODE, 2009).

Dados recebidos pela ANVISA mostram que as notificações de danos causados por produtos para alisamento capilar triplicaram no $1^{\circ}$ semestre de 2009 em comparação com todo o ano de 2008, sendo que na maioria dos casos há suspeita do uso indevido de formol (e também de glutaraldeído) como substâncias alisantes (ANVISA, 2009).

A maior preocupação em relação à segurança dos produtos cosméticos decorre principalmente do fato desses produtos serem considerados de venda livre, onde o consumidor pode adquiri-los quando desejar, sem a interferência de um profissional da saúde (DE BRITO, 2014). Diante disto, a implantação do sistema de Cosmetovigilância tem como objetivo aumentar a comunicação entre fabricantes e consumidores, para facilitar a descoberta de efeitos indesejados decorrentes ao uso destes produtos. Para complementar esse sistema, a ANVISA implantou o Sistema Nacional de Notificações para a Vigilância Sanitária (NOTIVISA). Trata-se de um sistema informatizado na plataforma WEB (internet), em âmbito de atuação municipal, estadual, distrital ou federal, previsto pela Portaria do Ministério da Saúde de №1.660/2009. Através dele podem cadastrar-se profissionais de saúde ou instituições/entidades, no qual poderão notificar eventos adversos ou queixas técnicas através de formulário de notificação. Havendo casos confirmados ou suspeitos de reações adversas ou queixas técnicas sobre produtos, serão submetidos a uma avaliação feita pela ANVISA, de acordo com a gravidade e risco do problema ocorrido (BEHRENS; CHOCIAI, 2007).

Os dados referentes ás notificações servirão para subsidiar o SNVS, para identificar efeitos não desejados, nos produtos, aperfeiçoarem o conhecimento dos efeitos dos produtos e, quando indicado, alterar recomendações sobre modo de usar e cuidados e regularizar os produtos comercializados no país e, de forma geral, promover ações de proteção à saúde pública (BEHRENS; CHOCIAI, 2007).

A Gerência Geral de Cosméticos da ANVISA, juntamente com a ABIHPEC, realizou em 2011, um seminário sobre cosméticos voltado para o setor regulado. De acordo com o panorama exposto no evento, destacaram-se como produtos de maior número de notificações os alisantes capilares. Fato este, que corrobora a pesquisa da qualidade e segurança desses cosméticos, tendo em vista a necessidade de controle no uso, produção, manuseio e aparecimento de reações adversas (SOUZA, 2012). 
Com relação aos casos notificados, foram registrados de 2007 a 2015, 1.715 notificações no NOTIVISA, conforme demonstrado no Gráfico 1. Anteriormente, essas informações se perdiam pela inexistência de um sistema próprio para o seu registro, assim, na maioria das vezes, o problema não tinha o encaminhamento necessário, resultando no simples abandono do uso do produto pelo consumidor (ANVISA, 2015; BEHRENS; CHOCIAI, 2007).

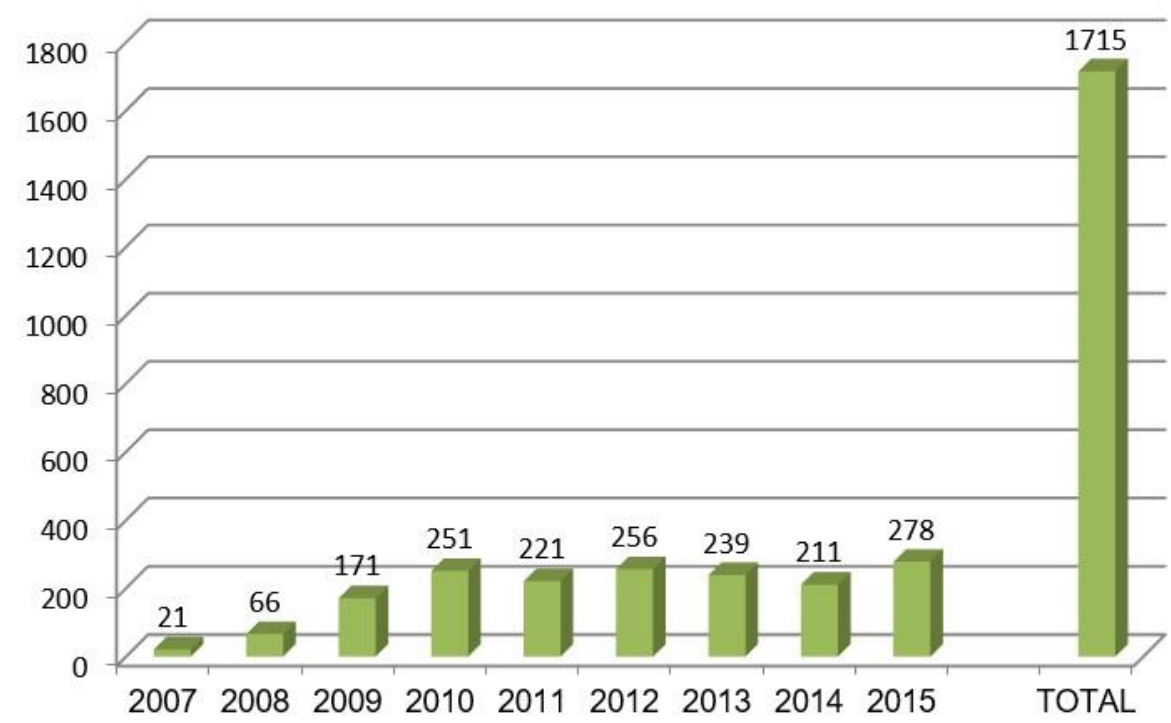

GRÁFICO 1: TOTAL DE NOTIFICAÇÕES DE EVENTOS ADVERSOS A COSMÉTICOS, POR ANO. NOTIVISA. BRASIL, 2007 A 2015.

FONTE: DADOS COM BASE NO SISTEMA NACIONAL DE NOTIFICAÇÕES PARA A VIGILÂNCIA SANITÁRIA (NOTIVISA), 2015.

As notificações foram iniciadas em 2006, com apenas uma notificação realizada. O gráfico demonstra no período de 2007 a 2010 uma pequena tendência de aumento das notificações, apesar do curto período de tempo de implantação do sistema NOTIVISA, mantendo uma constância entre os anos de 2010 a 2015. O maior número de notificações inseridas no sistema se refere ao ano de 2015, onde foram registradas 278 notificações, que equivalem a $16.2 \%$ do total em um universo de 1.715 casos, sendo registrados em média 190 casos anuais de eventos adversos por cosméticos.

O Gráfico 2 apresenta o total de casos registrados de intoxicação humana por cosméticos, no período de 2007 a 2013, disponibilizados pelo Sistema Nacional de Informação Tóxico Farmacológicas (SINITOX). O SINITOX, integrante da Fundação Osvaldo Cruz, criado em 1980, é responsável pela coleta, compilação, análise e divulgação 
dos casos de intoxicação e envenenamento registrados pela Rede Nacional de Centros de Informação e Assistência Toxicológica (RENACIAT). Os Centros possuem a função de fornecer informação e orientação sobre diagnóstico, prognóstico, tratamento e prevenção das intoxicações, assim como sobre a toxicidade das substâncias químicas e biológicas e os riscos que elas oferecem à saúde (BOCHNER; SOUZA, 2008).

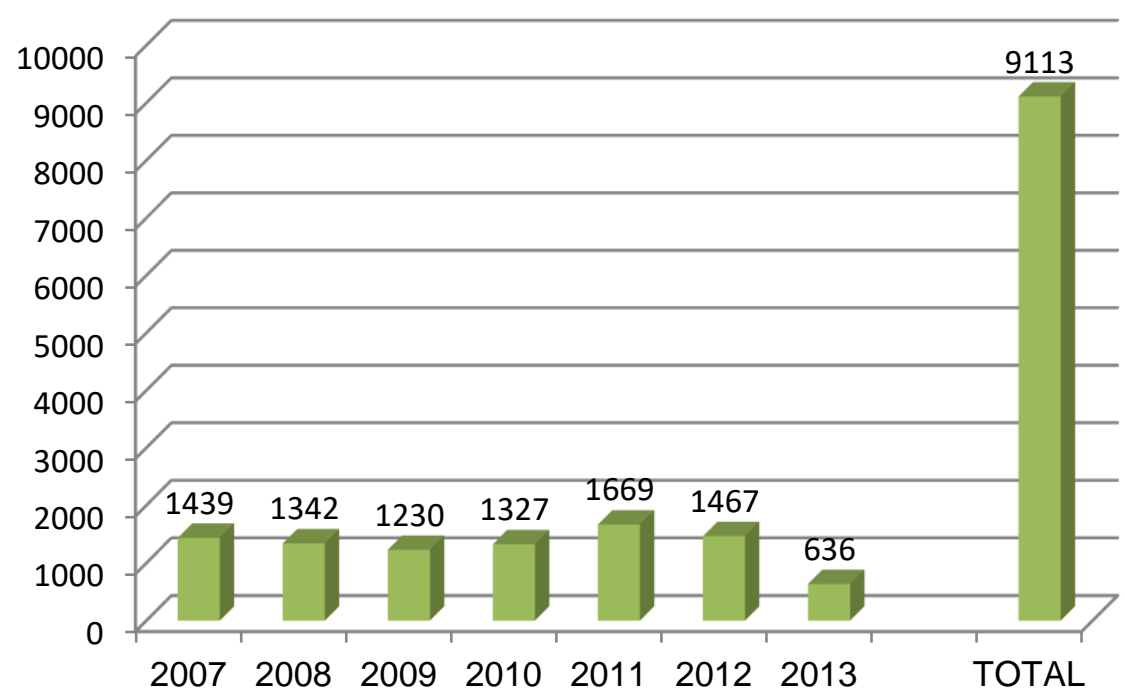

GRÁFICO 2 - TOTAL DE CASOS REGISTRADOS DE INTOXICAÇÃO HUMANA POR COSMÉTICOS. SINITOX. BRASIL, 2007 A 2013.

FONTE: DADOS COM BASE NO SISTEMA NACIONAL DE INFORMAÇÕES TÓXICOFARMACOLÓGICAS (SINITOX), 2009.

No gráfico acima, é importante mencionar que os dados apresentados se baseiam na tabela de "Casos Registrados de Intoxicação Humana por Agente Tóxico e Circunstância", do SINITOX, entre os anos de 2007 e 2013. Na mesma lista as seguintes circunstâncias: acidente individual, acidente coletivo, acidente ambiental, ocupacional, uso terapêutico, prescrição médica inadequada, erro de administração, automedicação, abstinência, abuso, ingestão de alimentos, tentativa suicídio, tentativa aborto, violência/homicídio, uso indevido, ignorada, outra.

Os dados mais recentes publicados nesse sistema indicam a ocorrência de 9.113 casos, totalizados, que foram registrados em decorrência a eventos de intoxicação humana por cosméticos no Brasil. Apesar da oscilação nos anos pesquisados, o patamar é alto para o número de casos de intoxicações, onde o maior número de casos identificados se dá no ano de 2011 , com 1.669 casos, que representam $18.3 \%$ do total. 
É importante salientar que os dados oficiais brasileiros sobre intoxicações por cosméticos não retratam a realidade do país, pois se encontram desarticulados e fragmentados em várias fontes de dados, neste caso temos os sistemas de dados do SINITOX e do NOTIVISA. Ambos são bancos nacionais de notificação, onde o primeiro registra dados de intoxicações e envenenamento notificados pela RENACIAT e o segundo notifica eventos adversos e queixas técnicas relacionadas com os produtos sob vigilância sanitária.

Pode ser observado que, existe um número maior de casos de intoxicações registrados pelo SINITOX, em relação ao número de notificações de eventos adversos do NOTIVISA, se supõe que essa diferença se dá pela falta de conhecimento sobre o sistema NOTIVISA, a consequência deste fato ocasionou um número reduzido de notificações de eventos adversos. A estatística de intoxicação e envenenamento no Brasil com base nos dois gráficos pode representar uma amostra significativa do que acontece na realidade e estas informações, depois de um tratamento adequado, sendo interpretadas por diferentes campos disciplinares, servem, assim, para intervir no mundo real.

Isto nos leva a crer, que deve ser dada maior atenção à qualidade dos produtos cosméticos que estão sendo desenvolvidos e lançados no mercado. Haja vista a necessidade de garantir que o produto final que chega até o consumidor seja seguro, respeitando os limites estabelecidos pela ANVISA, no que diz respeito aos limites das substâncias químicas.

\section{CONCLUSÃO}

Através do estudo realizado, conclui-se que existem relatos na literatura de reações adversas a cosméticos, embora não sejam desejáveis. Estas podem ocorrer de forma imediata, na primeira exposição ao produto, ou tardia, por efeito acumulativo, depois de repetidas aplicações.

Após analisar as substâncias nocivas como o ácido tioglicólico, o hidróxido de sódio, o hidróxido de cálcio, PPD, o peroxido de hidrogênio e o resorcinol, presentes nas formulações cosméticas, conforme seu potencial de causar efeitos adversos, observou-se que os cosméticos relacionados ao alisamento e tingimento capilar podem provocar sérios danos à saúde dos indivíduos expostos, quando utilizados inadequadamente.

Considerando, todos os resultados obtidos neste trabalho, é de extrema importância notificar reações adversas à ANVISA. Pois assim, é possível contribuir para 
que o sistema seja informado de situações que podem estar colocando em risco a saúde da população e, desta forma, possa agir criando normas restritivas e proibitivas.

Se faz necessário também além da formação e aperfeiçoamento dos profissionais que trabalham com esse tipo de produto, treinamentos e capacitações para que esses possam notificar aos órgãos competentes essas reações adversas para que assim possa se ter maiores informações sobre essas ocorrências e construírem uma forma melhor de resolver tal problemática.

Tais medidas são imprescindíveis, para se evitar reações adversas, sendo que as mais frequentemente relatadas são: irritação da pele, vermelhidão, queimaduras, lacrimação, hipersensibilidade, queda de cabelo e efeitos carcinogênicos, que podem ser decorrentes da inalação e exposição prolongada a produtos, principalmente quando estes apresentam concentrações acima do limite máximo permitido.

Em vista dos riscos tóxicos a que estão sujeitos os profissionais cabeleireiros e respectivos clientes, logo se nota a importância da implantação de uma política de Cosmetovigilância, como forma de garantir uma maior segurança e eficácia dos produtos cosméticos, bem como facilitar ao usuário o acesso a relatos sobre problemas de uso, defeitos de qualidade, efeitos indesejáveis, além de ser uma maneira de proibir e/ou coibir o uso indiscriminado de substâncias que podem se apresentar tóxicas.

\section{REFERENCIAS}

ABDI. Agência Brasileira de Desenvolvimento Industrial. Estudo prospectivo indústria de higiene pessoal, perfumaria e cosméticos, V. 13, 2009. Disponível em: <http://www.abdi.com.br com.br/Estudo/XIII.pdf>. Acesso em: 19 de outubro de 2019.

ABIHPEC. Associação Brasileira da Indústria de Higiene Pessoal, Perfumaria e Cosméticos. Caderno de tendências 2014-2015. Disponível em: <https://www.abihpec.org.br /2013/10/caderno-de-tendencias-2014-2015/>. Acesso em: 19 de setembro de 2019.

ABIHPEC. Associação Brasileira da Indústria de Higiene Pessoal, Perfumaria e Cosméticos. Panorama do setor de HPPC 2016. Disponível em: <https://www.abihpec.org.br /novo/wp-content/uploads/2016-PANORAMA-DO-SETORPORTUGU\%C3\%8AS-14jun2016.pdf>. Acesso em: 15 de setembro de 2019. 
ABIHPEC. Associação Brasileira da Indústria de Higiene Pessoal, Perfumaria e Cosméticos. Panorama do setor de HPPC 2014. Disponível em: < https://abihpec.org.br/ publicacao/panorama-do-setor-2014-2/>. Acesso em: 15 de setembro de 2019.

ABRAHAM, L. S. et al. Tratamentos estéticos e cuidados dos cabelos: uma visão médica (parte 2). Surgical \& Cosmetic Dermatology. v. 1, p. 178-185, 2009.

ANVISA. Agência Nacional de Vigilância Sanitária. A importância da Cosmetovigilância. Disponível em: <http://portal.anvisa.gov.br/cosmetovigilancia/saiba-mais>. Acesso em: 12 outubro de 2019.

Agência Nacional de Vigilância Sanitária. Guia para Avaliação de Segurança de Produtos Cosméticos. 20 edição, 2012. Disponível em: <http://www.saocamilosp.br/biblioteca/ebooks/Guia_cosmeticos_grafica_final.pdf $>$. Acesso em: 20 de novembro de 2019.

Agência Nacional de Vigilância Sanitária. Resolução RDC no 36, de 17 de junho de 2009. Disponível em: <http://www.anvisa.gov.br/cosmeticos/legis/rdc36_2009.pdf>. Acesso em: 20 de novembro de 2019.

Agência Nacional de Vigilância Sanitária. Resolução RDC no 48, DE 25 de outubro de 2013. Disponível em: <http://portal.anvisa.gov.br/documents/33880/2568070/rdc0048_ 25_10_2013.pdf/608ab1e6-1258-444d-b04c-86c6e35ead14>. Acesso em: 20 de novembro de 2019.

Agência Nacional de Vigilância Sanitária. Resolução RDC n 4, de 30 de janeiro de 2014. Disponível em: <http://bvsms.saude.gov.br/bvs/saudelegis/anvisa/2014/rdc0004_ 30_01_2014.html>. Acesso em: 20 de novembro de 2019.

Agência Nacional de Vigilância Sanitária. Relatório de Atividades Anvisa 2015. Disponível em: <http://portal.anvisa.gov.br/documents/281258/2742545/Relat\%C3\%B3rio+ de+Atividades+Anvisa+2015/a0a8d532-eeb4-45d5-9423-392b80350956>. Acesso em: 12 de agosto de 2019.

BEHRENS, Isabela; CHOCIAI, Jorge Guido. A cosmetovigilância como instrumento para a 
garantia da qualidade na indústria de produtos cosméticos. Visão Acadêmica, v. 8, n. 1 p.31-35, 2007.

BOCHNER, R.; SOUZA, V. M. F. A. Panorama das intoxicações e envenenamentos registrados no Brasil pelo Sistema Nacional de Informações Tóxico-Farmacológicas (SINITOX). Revista Racine, São Paulo, n. 106, v. 18, p. 44-58, 2008.

BRASIL. Anvisa proíbe cosmético com formol em excesso. Disponível em: http://www.brasil.gov.br/saude/2016/09/anvisa-proibe-cosmetico-com-formol-em-excesso>. Publicação: 08 de setembro de 2016. Acesso em: 06 de outubro de 2019.

BRASIL. Autorizado uso de acetato de chumbo em tintura de cabelo. Disponível em: <http://www.brasil.gov.br/saude/2013/03/autorizado-uso-de-acetato-de-chumbo-em-tintura -de-cabelo >. Publicação: 28 de março de 2013. Acesso em: 08 de outubro de 2019.

BRASIL. Cartilha sobre alisantes: Orientações quanto ao uso correto, cuidados e precauções necessárias, 2007. Disponível em: <http://www.anvisa.gov.br/cosmeticos/alisantes/ folder_alisantes/alisantes.htm>. Acesso em: 08 de outubro de 2019.

CHORILLI, M. et al. Ensaios biológicos para avaliação de segurança de produtos cosméticos. Revista de Ciências Farmacêuticas Básica e Aplicada. São Paulo, v. 30, n. 1, p. 10-21, 30 jan. 2009.

CVS. Centro de Vigilância Sanitária. Cosmetovigilância. Disponível em: <http://www.cvs.saude.sp.gov.br/apresentacao.asp?te_codigo=25>. Publicado em: 26 de abril de 2012a. Acesso em: 12 de novembro de 2019.

CVS. Centro de Vigilância Sanitária. Formol e Glutaraldeído como alisantes - Diga NÃO ao Uso Indevido. Disponível em: <http://www.cvs.saude.sp.gov.br/ler.asp?nt_codigo=21\&nt_tipo= 0\&te_codigo=7>. Publicado em: 27 de abril de 2012b. Acesso em: 12 de novembro de 2019.

DELFINI, F. N. A.; SCARPA, M. V.; CORRÊA, M. A. Ativos alisantes em cosméticos. 2011. 53 f. Trabalho de Conclusão de Curso - Curso de Graduação em Farmácia-Bioquímica, UNESP, Araraquara, 2011. 
DIAS, T. C. et al. Relaxing/straightening of Afro-ethnic hair: historical overview. Journal of Cosmetic Dermatology, n. 6, p. 2-5, 2007.

DOU - Diário oficial da União. RDC N 07, de 10 de fevereiro de 2015. Disponível em: <http://pesquisa.in.gov.br/imprensa/jsp/visualiza/index.jsp?data=11/02/2015\&jornal=1\&pa gina=39\&totalArquivos=136>. Acesso em: 10 de outubro de 2019.

FERREIRA, L. A.; BRAGA, D. C. Substâncias ativas do alisamento capilar e seus mecanismos de ação acumulação. Eletronic Journal of Pharmacy, v. XIII, n. 2, p. 56-63, 2016.

GOMES, R. K.; DAMAZIO, M. G. Cosmetologia: descomplicando os princípios ativos. 4. ed. São Paulo: Livraria Médica Paulista Ltda, p.145, 153, 200, 2013.

INCA. Instituto Nacional do Câncer. Formol ou Formaldeído. Rio de Janeiro (RJ). Disponível em: <http://www.inca.gov.br/conteudo_view.asp?id=795>. Acesso em: 19 de outubro de 2019.

KASI, R. A. P. et al. Para-phenylenediamine-induces apoptosis via a pathway dependent on PTK-Ras-Raf-JNK activation but independent of the PI3K/Akt pathway in NRK-52E cells. Molecular Medicine Reports, v. 11, p. 2262-2268, 2015.

KLAASSEN, C. D. \& WATKINS III J. B. Fundamentos em Toxicologia de Casarett e Doull (Lange). $2^{\underline{a}}$ ed. AMGH, Porto Alegre, p. 9, 2012.

LEONARDI, G. R. Cosmetologia aplicada. 2 ed. São Paulo: Ed. Santa Isabel. p. 2-5, 34-45, 2008.

LYRIO, E. S. et al. Recursos vegetais em biocosméticos: conceito inovador de beleza, saúde e sustentabilidade. Natureza online, v. 9, n. 1, p. 47-51, 2011.

MACAGNAN, Karyn Kristyni; SARTORI, Mara Rubia Keller; CASTRO, Fábio Godinho. Sinais e sintomas da toxicidade do formaldeído em usuários de produtos alisantes capilares. 4. ed. Curitiba: Cadernos da Escola de Saúde, v. 1, n. 4, p. 46-63, 2011.

MACHADO, L. S. et al. Aspectos toxicológicos relacionados ao uso de cosméticos na conservação, alisamento e tingimento capilar: Uma revisão de literatura. Revinter, v. 10, n. 01, p. 05-18, fev. 2017. 
MARCONI, M. A.; LAKATOS, E. M. Fundamentos de metodologia científica. 7 ed. São Paulo: Atlas, 2010.

OLASODE, O. A. Chemical hair relaxation and adverse outcomes among Negroid womwn in South West Nigeria. Journal of Pakistan Association of Dermatologists. 19, p. 203-207, 2009.

OLIVEIRA, Ricardo A. G. de et al. A química e toxicidade dos corantes de cabelo. Química Nova, São Paulo, v. XY, p.1-10, maio 2014.

PRISCILA, N. R. et al. Reações adversas aos produtos cosméticos e o Sistema de Notificação em Vigilância Sanitária: um inquérito. Revista Brasileira de Epidemiologia, v. 16, n. 4, p. 1017-1020, 2013.

PORTILHO, Debora. Altura: 675 pixels. Largura: 133 pixels. 13,1 KB. Formato JPG. Disponível em: <https://deboraportilho.wordpress.com/2014/01/15/o-problema-do-acidoglioxilico-na-escova-progressiva/>. Acesso em: 08 de outubro de 2019.

SANTOS, Hamilton. Toxicologia: a garantia de cosméticos seguros. Cosmetcs \& Toiletris, São Paulo, v. 20, n. 2, p. 20-23, mar./abril. 2008.

SILVA, F. M. et al. Orientações sobre os principais alisantes químicos utilizados em alisamentos capilares de acordo com a legislação brasileira. 2017. 15 f. Trabalho de Conclusão de Curso - Curso de Tecnologia em Estética, UTP, Curitiba.

SOUZA, A. M. F. Avaliação da segurança de alisantes capilares e monitoramento da limpeza como estratégia da qualidade na indústria cosmética. 2012. 93 f. Dissertação de mestrado - Pós-graduação em Ciências Farmacêuticas, UFPE, Recife.

VARELA, A. E. M. Um estudo sobre os princípios ativos dos produtos para alisamento e relaxamento de cabelos oferecidos atualmente no mercado brasileiro. 2007. 22 f. Trabalho de Conclusão de Curso - Curso de Tecnologia em Cosmetologia e Estética, UNIVALI, Santa Catarina. 